\title{
ОСОБЛИВОСТІ ЧИСЕЛЬНОГО ВИРІШЕННЯ ДИФЕРЕНЦІЙНИХ РІВНЯНЬ МОДЕЛЕЙ ЛАНЧЕСТЕРСЬКОГО ТИПУ У СТОХАСТИЧНІЙ ПОСТАНОВЦІ
}

У статті приведений короткий огляд можливої сфери застосування модифікацій моделей ланчестерського типу, а також розглянуті деякі особливості чисельного вирішення диференційних рівнянь таких моделей у стохастичній постановці. Стохастична постановка дозволяє ураховувати випадкові фактори та елементи невизначеності, які впливатимуть на динаміку змін чисельності протиборчих угруповань, $і$ які у певній мірі присутні у будь-яких бойових діях. На відміну від детермінованих моделей, стохастичні моделі потребують використання спечіальних методів, вибір конкретного з яких може трунтуватися на вимогах до ступеню їх збіжності на інтервалі інтегрування. Оцінка збіжності може слугувати також для перевірки правильності програмної реалізації обраного методу.

Ключові слова: моделі ланчестерського типу, стохастичні диференційні рівняння, методи чисельного вирішення, збіжність методу.

\section{Вступ}

Постановка проблеми. Інтерес до моделей ланчестерського типу, який простежується за регулярними публікаціями у тематичних періодичних виданнях, зокрема [1-9], свідчить про дієвість такого апарату для питань оперативного прогнозування змін у чисельності протиборчих угруповань в ході бойових дій. Так, у $[1 ; 3]$ зазначено, що навіть у складі потужних комплексів математичних моделей операцій (бойових дій) є необхідними та практично завжди використовується так звані експрес-моделі. Основним призначенням таких моделей $є$ проведення швидких оціночних розрахунків (без необхідності використання значного обсягу вихідних даних та обчислювального ресурсу) початкового співвідношення сил протиборчих сторін, а також прогнозування ймовірного ходу та результатів дій, що плануються. $€$ зрозумілим, що для таких задач використовується переважно арсенал аналітичного моделювання. Особливе місце у цьому класі займають моделі ланчестерського типу, до переваг яких можна віднести ясний фізичний зміст складових, які можуть входити у різні модифікації рівнянь (наслідком чого є можливість зрозумілим чином інтерпретувати отримані результати), оперативність отримання результатів та контрольованість проведення розрахунків. Достатньо перспективним напрямками модифікації моделей зазначеного типу (для підвищення адекватності моделей шляхом наближення опису за їх допомогою реалій бойових дій), слід вважати використання змінних (що залежать від часу) коефіцієнтів бойової ефективності, інтенсивності поповнення (зменшення) чисельності угруповань, а також урахування невизначеностей різного характеру у вигляді стохастичних складових у диференційних рівняннях. Оскільки відомості щодо ймовірних намірів противника носитимуть, здебільшого, лише прогнозний характер, урахування динамічних коефіцієнтів у відповідних диференційних рівняннях можливе у вигляді розподілів величин, вигляд яких обиратиметься виходячи 3 наявних даних про противника або виходячи 3 інших, суто практичних міркувань. С очевидним, що оперативність вирішення навіть лінійних диференційних рівнянь у складі ланчестерських моделей досягається лише при використанні чисельних методів, урахування динамічних коефіцієнтів переводить такі рівняння до розряду нелінійних, що робить використання чисельного інтегрування єдиним шляхом отримання результатів за такими моделями. Однак, імітація впливу різного роду випадкових чинників на хід бойових дій шляхом введення стохастичних складових у рівняння ланчестерських моделей обумовлює необхідність представлення їх у формі стохастичних диференційних рівнянь (СДР), для вирішення яких відомі та апробовані чисельні методи (типу методів Рунге-Кутти різних порядків точності, або модифікацій методу Ейлера) неефективні. Методи вирішення СДР та їх систем відрізняються від згаданих методів чисельного інтегрування, вони мають ряд особливостей, урахування яких для отримання прийнятних результатів за моделями ланчестерського типу у стохастичній постановці представляється достатньо актуальним науковопрактичним завданням.

Аналіз останніх досліджень і публікацій. Незважаючи на те, що хрестоматійний вигляд рівнянь був запропонований (незалежно один від одного) Осіповим та Ланчестером ще на початку 20-го сторіччя, такі моделі знаходять подальший теоретичний розвиток і сьогодні, що відзначається, зокрема, у публікаціях [1-9]. Дослідження у сфері складних 
військових систем, результати яких узагальнюються у приведених джерелах, показують, що модифікації ланчестерських моделей представляються достатньо ефективним інструментом їх якісного аналізу та виявлення нових закономірностей їх розвитку при урахуванні нелінійних співвідношень між параметрами систем. Проте, хоча у роботі [4] відзначена перспективність такого напрямку розвитку ланчестерських моделей, як перевід їх у вигляд СДР, а у [1] деталізовані способи імітації випадкових процесів у диференційних рівняннях, у всіх зазначених роботах розгляд питань вирішення СДР та їх систем залишений поза увагою. Такі питання набувають ще більшої актуальності зважаючи на те, що, на відміну від відомих методів чисельного інтегрування, методи вирішення СДР у абсолютній більшості середовищ моделювання не реалізовані, тобто вони потребуватимуть програмної реалізації з одночасною перевіркою отриманих характеристик відповідним теоретичним положенням.

Метою статті $\epsilon$ розгляд особливостей вибору та реалізації методів вирішення СДР у моделях ланчестерського типу.

\section{Виклад основного матеріалу}

Детальний аналіз та класифікація моделей ланчестерського типу приведений у [6]. Розглянувши та проаналізувавши більшість існуючих класичних постановок, автор [6-7] приходить до справедливого висновку, що такі моделі можна вважати певною мірою “ідеальними”, пристосованими для ідеальних умов. Реальні конфлікти відрізнятимуться, насамперед, за часом, тривалість їх буде визначатися надходженням різного роду ресурсів (людських, матеріальних) та впливом інших, зокрема й випадкових чинників. Тому, фактично, у рівняннях повинен знаходитися член, впливом на який можна “регулювати” тривалість збройного конфлікту та перевагу тієї чи іншої сторони. Таке твердження знайшло відображення у наступному узагальненому запису системи рівнянь у так званій “м'якій”, нелінійній постановці:

$$
\begin{aligned}
& \frac{d x}{d t}=-c(x, y) y(t)-d(t) \\
& \frac{d y}{d t}=-g(x, y) x(t)-h(t),
\end{aligned}
$$

де $x, y$ - чисельності протиборчих угруповань;

$c, g$ - змінні коефіцієнти, що відображають інтенсивності втрат від впливу противника;

$d, h$ - вільні члени рівнянь, які відображають надходження різного роду резервів та вплив інших чинників.

Необхідно відзначити, що вільні члени рівнянь вигляду (1) $d(t)$ та $h(t)$ можуть відігравати роль не тільки відображення надходження (збитку) різного роду ресурсів, а і взагалі впливу зовнішнього середовища, що часто використовується у моделях популяційної динаміки. У стохастичній постановці вільні члени рівнянь ланчестерського типу, що використовуватимуться в якості експрес-моделей прогнозування ходу бойових дій, також можуть відображати важкопрогнозовані випадкові чинники, які природнім чином присутні протягом ведення бойових дій. Як відомо [10], у загальному випадку під стохастичним диференційним рівнянням розуміється диференційне рівняння, у якому один член або більше відображають стохастичний процес. Найбільш відомий та достатньо поширений у практиці приклад СДР - це рівняння з членом, що описує так званий вінерівський випадковий процес (форма Ланжевена у інтерпретації Іто або Стратоновича):

$$
d x=a(x) d t+b(x) d W .
$$

Як видно з форми рівняння (2), воно складається зі звичайного (не стохастичного) диференційного рівняння та додаткової частини, що описує вінерівський шум $(d W)$.

Зазвичай вінерівський шум реалізується як $d W=\varepsilon \sqrt{d t}$, де $\varepsilon=\left(\varepsilon_{\downarrow} 1, \varepsilon_{\downarrow} 2, \ldots, \varepsilon_{\downarrow} n\right)$ та $\varepsilon_{i} \sim N(0,1)-$ нормальний розподіл $з$ нульовим середнім та одиничною дисперсією. Хоча, взагалі, у якості випадкового процесу можна використовувати будь-який напівмартингал, практичне застосування знайшли саме вінерівський та пуасонівський процеси.

Приведення рівнянь моделей ланчестерського типу до стохастичної форми у приведеній вище постановці не викликає труднощів, параметри розподілів випадкових процесів (нормального або пуасонівського) при цьому обираються, як зазначалося, виходячи з наявних даних про умови ведення бойових дій. Але методи їх чисельного вирішення будуть відрізнятися від загальновідомих методів чисельного інтегрування [11-12], при цьому необхідно зазначити, що вони (у своїй більшості) $є$ своєрідними стохастичними аналогами розкладання у ряд Тейлора. Серед таких методів порівняною простотою для програмної реалізації та необхідних подальших перевірок відрізняються наступні: метод ЕйлераМураями, метод Мільштейна та сильний метод Тейлора (іноді зустрічається його найменування як методу Burrage-Platen). Їх відмінність полягає, насамперед, у збіжності, поняття якої полягає у наступному. Припустимо, що $X(t)$ - рішення СДР на ділянці $[0 ; T]$, така ділянка розбита рівними кроками розмірності $h$. Нехай $Y(t)$ - деяка дискретна апроксимація $X(t)$, що розрахована за допомогою модифікованого чисельного методу у певних точках розбиття ділянки $[0 ; T]$. У такому випадку вважається, що чисельний метод сильно сходиться до $X(t)$ у момент часу $T$, якщо $\lim _{h \rightarrow 0} E\{|X(t)-Y(t)|\}=0$, де $E$ - ма- 
тематичне очікування. Вважається також, що чисельний метод збігається сильно до $X(t)$ у момент часу $T$ з порядком $\gamma>0$, якщо існує деяка константа $C>0$, що не залежить від $h$, а також число $\delta>0$ таке, що $\lim _{h \rightarrow 0} E\{|X(t)-Y(t)|\} \leq C h^{\gamma}$, для усіх $h \in(0 ; \delta)$. Змістовно, поняття сильної збіжності означає, що при усіх достатньо малих значеннях кроку інтегрування $h$ середнє значення похибки у кінцевій точці $t=T$ буде обмежуватись величиною кроку у ступеню $\gamma$, множеної на деяку константу, яка не залежить від $h$. Чим більше значення $\gamma$, тим скоріше збігається метод при зменшенні кроку $h$. Так, якщо метод матиме порядок збіжності 1, це означатиме, що при зменшенні кроку інтегрування вдвічі слід очікувати не менше ніж двократного зменшення похибки у точці $t=T$. Необхідно також відзначити, що у теорії СДР існує також поняття слабкої збіжності, яке у даному випадку не розглядається. Перелічені вище методи мають наступні порядки збіжності: метод Ейлера-Мураями - 1/2; метод Мільштейна - 1 ; метод Тейлора $-1,5$.

Для наочності та в якості прикладу припустимо, що для програмної реалізації обраний метод Мільштейна, для перевірки правильності його реалізації можна використати тестове модельне рівняння вигляду:

$$
d S_{t}=S_{t}\left(r d t+\sigma d W_{t}\right), \quad S_{0}>0
$$

3 аналітичним рішенням виду:

$$
S_{t}=S_{0} e^{\left(r-\frac{\sigma^{2}}{2}\right) t+\sigma W_{t}},
$$

де $r, \sigma$ - постійні коефіцієнти, що ураховують випадковий характер функції виду $S_{t}$.

Тоді чисельний метод Мільштейна для вирішення СДР можна записати у вигляді:

$$
\begin{gathered}
S_{i+1}=S_{i}+S_{i}\left(r h+\sigma \Delta W_{i}\right)+\frac{1}{2} \sigma^{2} S_{i}\left(\left(\Delta W_{i}\right)^{2}-h\right), \\
S_{0}=s_{0},
\end{gathered}
$$

де $\Delta W_{i}=N(0,1) h^{1 / 2}-$ приріст випадкового вінерівського процесу.

Наявність точного аналітичного рішення $X(t)$ за (4) тестового рівняння виду (3) дає змогу перевірити програмну реалізацію обраного методу чисельного інтегрування СДР. Практична організація перевірки реалізації методу Мільштейна полягає у отриманні

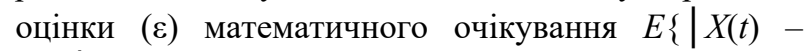
$Y(t) \mid$ \} як:

$$
\varepsilon=\frac{1}{n P_{a t} s} \sum_{k=1}^{n P_{h} s}\left\{\left|X^{k}(T)-Y^{k}(T)\right|\right\},
$$

де $n P a t_{h} s$ - кількість траєкторій, отриманих для точного $X^{k}(T)$ та приблизного чисельного $Y^{k}(T)$ рішення відповідно.
Приклад результатів перевірки реалізації обраного методу представлений у табл. 1 для наступних умов: $S_{0}=100 ; r=0,05 ; \sigma=0,2 ; T=2 ; n$ at $_{h} s=1000$.

Таблиця 1

Результати визначення оцінки математичного очікування ( $\varepsilon$ ) за (6) методом Мільштейна

\begin{tabular}{|c|c|}
\hline$h$ & $\varepsilon$ \\
\hline 0,75 & 1,188427 \\
\hline 0,375 & 0,615952 \\
\hline 0,1875 & 0,317242 \\
\hline 0,09375 & 0,160855 \\
\hline 0,046875 & 0,081216 \\
\hline 0,023438 & 0,040229 \\
\hline 0,011719 & 0,0206 \\
\hline 0,005859 & 0,010176 \\
\hline
\end{tabular}

Отримані результати підтверджують правильність програмної реалізації обраного методу вирішення СДР та його відповідність характеристикам збіжності, що дає змогу використати реалізацію для вирішення, наприклад, такого вигляду ланчестерської моделі з урахуванням поповнення чисельності сторін в ході бойових дій:

$$
\begin{aligned}
& \frac{d x}{d t}=-\lambda_{2} y+\mu_{1}\left(N_{1}-x\right), x(0)=N_{1} ; \\
& \frac{d y}{d t}=-\lambda_{1} x+\mu_{2}\left(N_{2}-y\right), y(0)=N_{2},
\end{aligned}
$$

де $N_{1,2}-$ початкові чисельності протиборчих угруповань;

$\lambda_{1,2}-$ інтенсивності вражаючої дії бойових одиниць сторін;

$\mu_{1,2}$ - інтенсивності відновлення чисельності угруповань.

Графічне відображення вирішення системи рівнянь (7) методом Рунге-Кутти 4 порядку точності та методом Мільштейна показане на рис. 1 та рис. 2 відповідно. Рішення отримані для наступних умов: $N_{1}=30 ; N_{2}=90 ; \lambda_{1}=2 ; \lambda_{2}=3 ; \mu_{2}=0$; параметр $\mu_{1}$ на рис. 1 $\epsilon$ функцією часу і змінюється лінійно від 1 до 10 на протязі 3 одиниць часу; на рис. 2 є стохастичною функцією $\mu_{1} d W$.

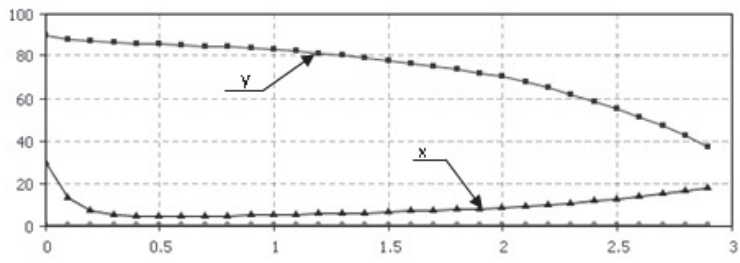

Рис. 1. Графічне відображення результатів вирішення систем рівнянь (детермінована модель) 


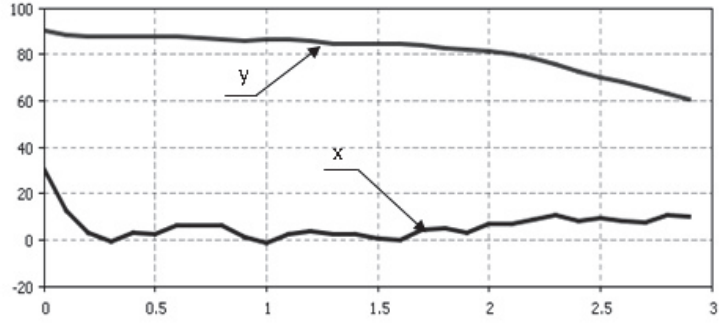

Рис. 2. Графічне відображення результатів вирішення систем рівнянь методом Мільштейна (стохастична модель)

Припускаючи (для прикладу), що мова йде про моделювання дій тактичного рівня на протязі трьох годин бою, можна зазначити наступне. Урахування випадкових чинників, які можуть впливати на відновлення чисельності угруповання з об'єктивних причин, достатньо вагомо відображається на динаміці змін чисельності сторін. Так, при використанні звичайної ланчестерської моделі чисельність сторони $x$ після трьох годин бою (з урахуванням поступового відновлення чисельності) складатиме близько 67 \% початкової чисельності. При використанні стохастичної складової у рівняннях моделі і вирішенні системи рівнянь відповідним чисельним методом за аналогічних умов така чисельність становить вже близько 33 \% від початкового значення. Така різниця представляється достатньо значною, при цьому (за коректного представлення впливу випадкових чинників - вогневого ураження противника, характеру місцевості, пори року або погодних умов тощо) стохастичний вигляд рівнянь ланчестерських моделей можна вважати більш наближеним до реалій бойових дій. Інакше кажучи, представлення рівнянь ланчестерських моделей у стохастичній формі та урахування всіх особливостей їх чисельного вирішення має на меті розширення можливостей моделей зазначеного типу щодо опису бойових дій, та, у кінцевому випадку, підвищення їх адекватності.

\section{Висновки}

Моделі ланчестерського типу та їх численні модифікації залишаються достатньо ефективним інструментом якісного аналізу та виявлення нових закономірностей динамічних військових систем при урахуванні нелінійних співвідношень між їх параметрами. Одним $з$ напрямків розвитку моделей зазначеного типу $є$ приведення диференційних рівнянь моделей до стохастичного виду з метою урахування випадкових чинників, які впливатимуть на хід та результати бойових дій і які у тій чи іншій мірі присутні при їх веденні.

Основними особливостями, які потребуватимуть урахування при відображені стохастичної частини та виборі методу чисельного вирішення стохастичних диференційних рівнянь у моделях ланчестерського типу, є: коректний вибір виду та параметрів розподілу випадкових факторів, суттєвих для урахування в моделі; вибір методу чисельного вирішення стохастичних рівнянь, який за своїми характеристиками (насамперед - збіжністю) відповідає вимогам до результатів моделювання; перевірка відповідності реалізованого методу теоретичним положенням щодо його характеристик.

Представлення рівнянь моделей ланчестерського типу у стохастичному вигляді дозволить наблизити такі моделі до реалій бойових дій та сприятиме підвищенню їх адекватності.

\section{Список літератури}

1. Горевич Б.Н. Применение элементов имитации в дифференциальных моделях военных действий / Б.Н. Горевич // Вооружение и экономика. - 2010. - № 2(10). - С. 31-41.

2. Брезгин В.С. Уравнения динамики боевых потенциалов противоборствующих группировок / В.С. Брезгин, А.И. Буравлев // Вооружение и экономика. - 2011. - № 1(13). -С. 59-65.

3. Буравлев А.И. Дифференциальное уравнение для количественного соотношения численностей противоборствующих сторон / А.И. Буравлев // Вооружение и экономика. - 2009. - № 4(8). - С. 4-8.

4. Новиков Д.А. Иерархические модели военных действий / Д.А. Новиков // Управление большими системами: сб. трудов. - М.: ИПУ им. В. А. Трапезникова РАН, 2012. - Вып. 37. - С. 25-62.

5. Буравлёв А.И. Модель динамики противоборства неоднородных группировок сил / А.И. Буравлёв, С.В. Гордеев // Вооружение и экономика. - 2009. - № 1(5). - С. 13-25.

6. Митюков Н.В. К вопросу о типологии ланчестерских моделей / Н.В. Митюков // Круг идей: междисциплинарные подходы в исторической информатике: сб.; под ред. Л.И. Бородкина, И.М. Гарсковой. - М.: МГУ, 2008. - С. 375-399.

7. Митюков Н.В. Математические модели и программные средства для реконструкции военно-исторических данных: автореферат... докт. техн. наук: 07.00.09. - Ижевск, 2009. - 33 с.

8. Чуев В.Ю. Модели двусторонних боевых действий многочисленных группировок / В.Ю. Чуев, И.В. Дубограй // Математическое моделирование и численные методы. - 2016. - № 9. - С. 89-104.

9. Бутвін Б.Л. Використання модифікованих рівнянь динаміки середніх для оперативного прогнозування ходу та результатів бойових дій / Б.Л. Бутвін, О.О. Машкін, О.І.Соломицький // Сучасні інформаційні технології у сфері безпеки та оборони. - 2019. - № 2 (35). - C. 115-120. https://doi.org/10.33099/2311-7249/2019-35-2-115-120. 
10. Кузнецов Д.Ф. Стохастические дифференциальные уравнения: теория и практика численного решения / Д.Ф. Кузнецов. - СПб: Изд-во Политехн. ун-та, 2010. - 816 с.

11. Кулябов Д.С. Анализ трудностей реализации стохастических численных методов Рунге-Кутты / Д.С. Кулябов, М.Н. Геворкян, А.В. Демидова и др. // Труды II Международной научной конференции "Конвергентные когнитивноинформационные технологии" (Convergent'2017). - Москва, 24-26 ноября, 2017. - С. 28-40.

12. Степанов С.С. Стохастический мир [Електронний ресурс] / С.С. Степанов. - 2009. - 376 с. - Режим доступу: http://synset.com.

\title{
References
}

1. Gorevich, B.N. (2010), "Primeneniye elementov imitatsii v differentsial'nykh modelyakh voyennykh deystviy" [The use of imitation elements in differential models of military operations], Armament and Economics, No. 2(10), pp. 31-41.

2. Brezgin, V.S. and Buravlev, A.I. (2011), "Uravneniya dinamiki boyevykh potentsialov protivoborstvuyushikh gruppirovok" [Equations of dynamics of combat potentials of confrontational groups], Armament and Economy, No. 1(13), pp. 59-65.

3. Buravlev, A.I. (2009), "Differentsial'noye uravneniye dlya kolichestvennogo sootnosheniya chislennostey protivoborstvuyushchikh storon" [Differential equation for the quantitative ratio of the numbers of the warring parties], Armament and Economy, No. 4(8), pp. 4-8.

4. Novikov, D.A. (2012), "Iyerarkhicheskiye modeli voyennykh deystviy" [Hierarchical models of hostilities], International Services Management, Iss. 37, Moscow, pp. 25-62.

5. Buravlev, A.I. and Gordeev, S.V. (2009), "Model' dinamiki protivoborstva neodnorodnykh gruppirovok sil" [A model of the dynamics of the confrontation of heterogeneous force groups], Armament and Economy, No. 1(5), pp. 13-25.

6. Mytiukov, N.V. (2008), "K voprosu o topologii lanchesterskikh modeley" [On the question of the typology of Lanchester models], Circle of ideas: interdisciplinary approaches in historical computer science, Moscow, pp. 375-399.

7. Mytiukov, N.V. (2009), "Matematicheskiye modeli i programmnyye sredstva dlya rekonstruktsii voyenno-istoricheskikh dannykh: avtoreferat" [Mathematical models and software for the reconstruction of military-historical data: abstract], Izhevsk, $33 \mathrm{p}$.

8. Chuyev, V.Yu and Dubogray, I.V. (2016), "Modeli dvustoronnikh boyevykh deystviy mnogochislennykh gruppirovok" [Models of bilateral military operations of numerous factions], Mathematical Modeling and Numerical Methods, No. 9, pp. 89-104.

9. Butvin, B.L., Mashkin, O.O. and Solomitskii, O.I. (2019), "Vykorystannya modyfikovanykh rivnyan' dynamiky serednikh dlya operatyvnoho prohnozuvannya khodu ta rezul'tativ boyovykh diy" [The use of modified equation of dynamics of medium for operative forecasting of the cource and results of the combat actions], Modern Information Technologies in the Sphere of Security and Defense, No. 2(35), pp. 115-120. https://doi.org/10.33099/2311-7249/2019-35-2-115-120.

10. Kuznetsov, D.F. (2010), "Stokhasticheskiye differentsial'nyye uravneniya: teoriya i praktika chislennogo resheniya" [Stochastic differential equations: theory and practice of numerical solution], Politechnical University, St. Petersburg, $816 \mathrm{p}$.

11. Kulyabov, D.S., Gevorkyan, M.N., Demidova, A.V., Korolkova, A.V., Sevastianov, L.A. and Kotukov, M.M. (2017), "Analiz trudnostey realizatsii stokhasticheskikh chislennykh metodov Runge-Kutty" [Implementation difficulties analysis of stochastic numerical Runge-Kutta methods], Proceedings of the II International scientific conference "Convergent cognitive information technologies" (Convergent'2017), Moscow, Russia, pp. 28-40.

12. Stepanov, S.S. (2009), "Stokhasticheskiy mir" [Stochastic world], 376 p., available at: www.synset.com.

Надійшла до редколегії 26.12.2019

Схвалена до друку 11.02.2020

\section{Відомості про автора:}

\section{Машкін Олександр Олександрович}

кандидат технічних наук старший науковий співробітник начальник відділу Центрального науково-дослідного інституту Збройних Сил України, Київ, Україна https://orcid.org/0000-0002-3094-9984

\section{Information about the author:}

\author{
Olexander Mashkin \\ Candidate of Technical Sciences \\ Senior Research \\ Head of Department of Central Research Institute \\ of the Armed Forces of Ukraine, \\ Kyiv, Ukraine \\ https://orcid.org/0000-0002-3094-9984
}

\section{ОСОБЕННОСТИ ЧИСЛЕННОГО РЕШЕНИЯ ДИФФРЕНЦИАЛЬНЫХ УРАВНЕНИЙ МОДЕЛЕЙ ЛАНЧЕСТЕРСКОГО ТИПА В СТОХАСТИЧЕСКОЙ ПОСТАНОВКЕ}

\author{
А.А. Машкин
}

В статье приведен краткий обзор возможной сферы применения моделей ланчестерского типа, а также рассмотрены некоторые особенности численного решения дифференциальных уравнений таких моделей в стохастической постановке. Интерес к моделям ланчестеского типа, который прослежсивается по публикациям в тематических периодических изданиях, свидетельствует о действенности подобного аппарата для решения вопросов оперативного 
прогнозирования изменений в численности противостоящих группировок в ходе боевых действий. Кроме того, в составе многих современных комплексов математических моделей операций (боевых действий) часто используются так называемые экспресс-модели. Основным назначением таких моделей является проведение быстрых оценочных расчетов динамики изменения численности войск в различных условиях их применения. Использование экспресс-моделей не требует значительного объема исходных данных и вычислительного ресурса (в отличие от мощных комплексов моделей). Одним из возможных направлений модификации моделей ланчестерского типа с иелью приближения их к реалиям боевых действий является представление уравнений модели в стохастической форме. Стохастическая постановка позволяет учесть случайные факторы и элементы неопределенности, которые влияют на динамику изменений численности противостоящих группировок, и которые в определенной мере присутствуют в любых боевых действиях. В отличие от детерминированных моделей, стохастические модели требуют использования специальных методов, выбор конкретного из них может быть обоснован требованиями к степени их сходимости на интервале интегрирования. $B$ статье рассмотрен пример использования метода Мильштейна для численного решения дифференциальных уравнений ланчестерской модели в стохастической постановке. Показано также, что оченка сходимости выбранного для численного решения метода может служить для проверки правильности его программной реализации.

Ключевые слова: модели ланчестеского типа, стохастические дифференциальные уравнения, методы численного решения, сходимость метода.

\section{FEATURES OF NUMERICAL SOLUTION OF DIFFRENCIAL EQUATIONS OF LANCHESTER-TYPE MODELS IN STOCHASTIC PRODUCTION}

O. Mashkin

The paper provides a brief overview of the possible scope of application of Lanchester-type models, and discusses some features of the numerical solution of differential equations of such models in stochastic setting. The interest in Lanchester models, which can be seen from publications in thematic periodicals, shows the effectiveness of such an apparatus in solving issues of rapid forecasting of changes in the number of opposing factions during hostilities. In addition, many modern systems of mathematical models of operations (combat operations) often use so-called express models. The main purpose of such models is to carry out rapid estimates of the dynamics of changes in the number of troops under different conditions of their use. The use of express models does not require a significant amount of source data and computing resource (unlike powerful model complexes). One possible direction of modifying Lanchester-type models to bring them closer to the realities of combat is to represent the equations of the model in stochastic form. Stochastic production allows to take into account random factors and elements of uncertainty, which influence the dynamics of changes in the number of opposing groups, and which to a certain extent are present in any combat. Unlike deterministic models, stochastic models require the use of special methods, the choice of a particular one can be justified by the requirements for their degree of convergence at the integration interval. The paper examines an example of using the Milstein method to numerically solve the differential equations of the Lanchester model in stochastic production. It is also shown that the convergence estimation of the method chosen for the numerical solution can serve to verify the correctness of its software implementation.

Keywords: Lanchester-type models, stochastic differential equations, methods of the numerical decision, convergence of a method. 